\title{
El carnaval en la obra El público de Lorca
}

\section{The Carnival in the Dramatic Text The Public of Lorca}

O carnaval na obra O público de Lorca

\author{
Juan Enrique Mendoza Zazueta \\ Universidad Autónoma de Sinaloa, México \\ juanmendoza@uas.edu.mx \\ https://orcid.org/0000-0002-6597-2754
}

\section{Resumen}

La meta del presente trabajo es distinguir los diferentes niveles dramáticos que componen $E l$ público de Federico García Lorca. Para ello se utilizará la edición prologada por el doctor Huerta Calvo (2006). A la par de los comentarios sobre los niveles dramáticos, se intentará relacionar con el sentido transgresor carnavalesco y la estructura del texto dramático. Para ello nos valdremos de autores como Julio Huélamo Kosma (1996) para la interpretación y de José Luis García Barrientos (2012) para el análisis de los niveles dramáticos del texto, que nos ayuden a relacionarla con el tema propuesto por el autor.

Palabras clave: análisis, dramatología, Lorca, metadrama, teatro.

\section{Abstract}

The aim of this paper is to distinguish different dramatic levels inside The Public by Federico García Lorca. To do that, the edition with a foreword by Dr. Huerta Calvo (2006) will be used. Along with comments on those levels, this study will try to relate them to the transgressive sense of carnival and structural aspect of dramatic text. For this we will use authors such as Julio Huélamo Kosma (1996) for interpretation and José Luis García Barrientos (2012) for the analysis of the dramatic levels of the text, which help us to relate it to the theme proposed by the author.

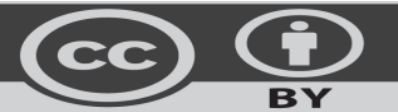




\section{Revista Iberoamericana \\ de las Ciencias Sociales y \\ Humanísticas}

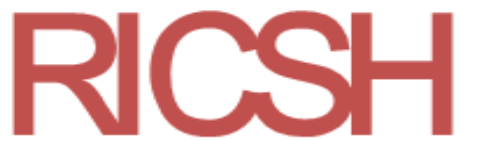

ISSN: $2395-7972$

Keywords: analysis, dramatology, Lorca, metadrama, theater.

\section{Resumo}

O objetivo deste artigo é distinguir os diferentes níveis dramáticos que compõem o público de Federico García Lorca. Para isso, será utilizada a edição aprovada pela Dra. Huerta Calvo (2006). Juntamente com os comentários sobre os níveis, tentaremos relacioná-los com o sentido carnavalesco-transgressivo. Embora neste caso os principais interesses tratem de um aspecto estrutural, vários estudos temáticos que foram realizados sobre o trabalho apoiarão. Para isso, utilizaremos autores como Julio Huélamo Kosma (1996) para interpretação e José Luis García Barrientos (2012) para a análise dos níveis dramáticos do texto, que nos ajudam a relacioná-lo com o tema proposto pelo autor.

Palavras-chave: análise, dramatologia, Lorca, metadrama, teatro.

Fecha Recepción: Octubre 2018

Fecha Aceptación: Diciembre 2019

\section{Introducción}

Hablar o escribir de la obra El público es abordar uno de los textos más interesantes, complejos y actuales. Si el teatro es la representación de la vida y una de sus aspiraciones es ser poesía, esto es, vida contenida dentro de una estructura, la obra escrita por el granadino en 1930 se convierte en un texto indispensable para comprenderlo. Esa obra, llamada irrepresentable por su autor, no tanto quizá porque el germen escénico no estuviera allí latente sino porque la sociedad no estaba lista para recibirla, es una obra adelantada a su tiempo, vanguardista y punta de lanza de su época. Las palabras del poeta Luis Cardoza y Aragón sobre los proyectos de Lorca son reveladoras. En una conversación, el español le contó “que iba a escribir el teatro que nadie se había atrevido a escribir por cobardía" (García, 2006, p. 104). Lorca hacía alusión, particular y muy probablemente, al texto La destrucción de Sodoma y Gomorra, del cual solo se conservan unos fragmentos.

Sin embargo, leamos El público y constatemos que esas mismas palabras le van a la perfección. 


\section{Revista Iberoamericana \\ de las Ciencias Sociales y \\ Humanísticas}

ISSN: $2395-7972$

La destrucción de Sodoma y Gomorra y El público comparten un tema tabú: la homosexualidad. Sobre la obra que nos ocupa, el poeta declaró en el periódico La nación de Buenos Aires:

Sí, mi pieza no es una obra para representarse es, como ya lo he definido, un poema para silbarlo, ese silbido se esconde o forma parte de un lenguaje que se escucha pero no se articula como palabra comprensible, es el teatro bajo la arena que encuentra una manera de expresión arriba, en donde está ese teatro al aire libre, dos espacios conjugados y separados a la vez por las barreras que forman las convenciones sociales (García, 2006, p. 17).

Al subvertir los códigos sociales, la obra genera un carnaval mediante la reproducción de una intención fantástica, opositora a esa intención realista, "enfrentando la verdad a la noverdad, a la falsedad, a la mentira. Es decir, a través de esa cadena de oposiciones, el camino queda trazado así; apariencia de fantasía-intencionalidad realista-representación de la verdad" (Hermenegildo, 1999, p. 59). Un viaje que parte de lo externo a la codificación en primer término realista, siguiendo códigos entendibles y aceptados, para llegar a un objeto íntimo.

\section{El pastor, gestor del carnaval}

Nuestro viaje, o ese viaje, el de Lorca en El público, inicia con una invitación. Es importante aclarar aquí que tomamos como bitácora la edición prologada por el maestro Huerta Calvo, en la que se coloca al inicio el "Solo del pastor bobo", como lo bautizó Martínez Nadal. Normalmente esta pieza es colocada a modo de compendio y enlace entre el cuadro cuarto y quinto de la obra; ${ }^{1}$ sin embargo, como ya se mencionó, en esta edición se ubica al principio. José Rubia Barcia no difiera de este acomodo, pues menciona que "debiera ofrecérsele al público como estampa inicial” (García, 2006, p. 24). En la edición que nos servirá para el trabajo, además, el "Solo del pastor bobo" aparece con una ligera variación en el título: "Loa del pastor bobo". En la tradición española, "la mayoría de estos autores encomendaba al Pastor Bobo la recitación del prólogo, más comúnmente llamado entonces

\footnotetext{
${ }^{1}$ En esta línea, el "Solo del pastor bobo" es una especie de epítome que cierra el cuadro anterior, pero que también sirve de enlace para el último cuadro, donde el Director se enfrenta a la última y definitiva versión de la "máscara", la muerte (Kosma, 1996).
} 


\section{Revista Iberoamericana \\ de las Ciencias Sociales y \\ Humanísticas}

ISSN: $2395-7972$

'introito', en el que se anticipaba el argumento de la comedia y se proferían bromas y hasta diatribas contra el público" (García, 2006, p. 25).

El pastor de El público da la bienvenida y prepara a su público en un primer proceso de actualización y dramatización de este, en una función pragmática orientada a los asistentes. García Barrientos menciona que esta función "se manifiesta en la apelación 'interna' hecha por el personaje desde dentro de la ficción; por ejemplo, mediante el 'aparte a los espectadores', tan frecuentado por el gracioso, precisamente para acercar al público a su punto de vista" (García, 2012, p. 179). La "Loa..." tiene un sentido claro de condicionar la visión del espectador: cómo debe de observar lo que vendrá. En este caso, su mirada debe ser a partir del despojo de la máscara de la apariencia, "de la mentira que sustenta a la sociedad" (Kosma, 1996, p. 68):

[Aquella] que justifica que las caretas que ahora aparecen sean recogidas por un pastor e incluso que balen como un fantasmagórico y ridículo hato en el que los individuos, enajenados por la vía del engaño, se han convertido en “ovejas" sin capacidad de rebeldía contra la mentira que los ahoga (Kosma, 1996, p. 68).

De esta manera, el pastor sale de escena llevándose las caretas para que la verdad gobierne el drama y se pueda representar lo oscuro, oculto y encerrado que el teatro bajo la arena propone, alterando el orden preestablecido, pues "vivir alineado es no vivir, es estar muerto" (Kosma, 1996, p. 68). Invitación a la liberación de los condicionamientos sociales y vivir sin tapujos. La obra, pues, requiere un público vivo, no muertos vivientes, caretas sin espíritu, aunque esto suponga la verdad y la muerte final.

El espectador entra a la sala y en el escenario se encuentra un armario lleno de caretas, máscaras. Posteriormente el pastor hará su entrada y dirigirá unas palabras al auditorio; un prólogo que establece un primer contacto, como ya mencionamos, con el espectador:

EL PASTOR. El pastor bobo guarda las caretas, las caretas

de los pordioseros y de los poetas

que matan a las gipaetas

cuando vuelan por las aguas quietas.

Careta

de los niños que usan la puñeta 


\section{Revista Iberoamericana \\ de las Ciencias Sociales y \\ Humanísticas}

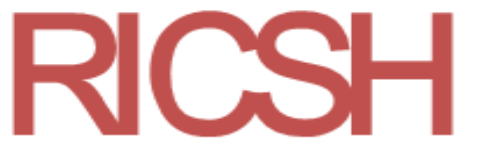

ISSN: $2395-7972$

y se pudren debajo de una seta (García, 2006, p. 100).

El pastor/actor guarda las caretas. Es así como introduce al espectador en una supuesta ilusión teatral, otra máscara creada por el hombre. Pero la loa dicha por el pastor tiene una función de "impugnación social, la esencia crítica del drama” (Kosma, 1996, p. 261). Cuestionamiento social realizado por alguien "vestido con pieles bárbaras y embudo lleno de plumas" (García, 2006, p. 100) en la cabeza que delata su procedencia salvaje. Un mundo en donde se exaltan los placeres de la carne, los instintos, la naturaleza, "la agresividad contra los comportamientos más intolerantes e hipócritas de la sociedad" (Huerta, 1999, p. 32). Personaje poco serio es ese que viene a aconsejar al auditorio, un ser de carnaval, época en la que esos excesos son tolerados.

La "Loa..." posiciona al espectador en un primer drama, en un recorrido que los coloca en el escenario del mundo. El edificio teatral se transforma en síntesis de la tierra; el público, en actores que se suman a los del drama sobre ese escenario, que desde un palco de estrellas es contemplado por la gran máscara, la moral social. Este será el primer nivel, círculo formado por ese palco celestial en donde las calles, plazas, atrios, se convierten en el tablado para representar la farsa que es la vida misma. El primer círculo que se cierra con la enumeración de los diferentes escenarios del mundo:

EL PASTOR. ¡Balad, balad, balad, caretas!

Europa se arranca las tetas,

Asia se queda sin lunetas

y América es un cocodrilo

que no necesita careta (García, 2006, p. 102).

Los espectadores balan, los actores balan, las masas balan. Parodia irónica. El público asistente se encuentra inmerso en un espejo deformado, el espejo de la verdad, y desde esta perspectiva tendrá que observar el drama. Cultura chocante con la vida en ese juego carnavalesco. 


\section{Revista Iberoamericana \\ de las Ciencias Sociales y \\ Humanísticas}

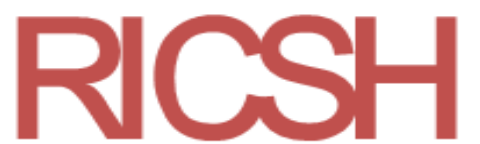

ISSN: $2395-7972$

\section{El juego de niveles}

La "Loa del pastor bobo" da acceso a lo que sería un drama enmarcado. Aunque las alusiones sígnicas que nos presenta hacen referencia al teatro, lo cual nos llevaría a considerar la obra como metateatral, a saber, "forma genuina del 'teatro en el teatro' que implica una puesta en escena teatral dentro de otra (un actor real representando a un actor teatral representando a un personaje dramático)" (García, 2012, p. 232). El pastor funciona como una especie de presentador del segundo drama, lo que acerca la obra a un metadrama.

Entiendo un concepto más amplio, que incluye al anterior, pero que lo rebasa en todas aquellas manifestaciones en que el drama secundario, interno o de segundo grado se escenifica efectivamente, pero no se presenta como producido por una puesta en escena, sino por un sueño, un recuerdo, la acción verbal de un "narrador”, etcétera (García, 2012, p. 232).

Es la acción del pastor la que origina la entrada a esta primera caja china, a partir de esta presentación del drama.

La codificación que la tradición del teatro español ha realizado sobre este personaje genera en el espectador un distanciamiento, esto es, no produce una identificación, sino más bien una distancia: "la distancia implica, pues, 'opacidad' de la representación que se deja notar, en vez de transparentar - haciéndose invisible - el mundo representado, como ocurre cuando domina la ilusión de realidad" (García, 2012, p. 195).

El telón se abre. Regresamos otra vez a la idea del teatro dentro del teatro, pero esta vez, al abrirse el telón, los personajes que pueblan la escena habitan un mundo teatral tras bastidores; estamos en la parte trasera del teatro, allí donde la vista del espectador no llega nunca. El teatro acusa a la realidad y la devela, la descubre. "El teatro se debe imponer al público y no el público al teatro" (Martínez, 1974, p. 246). Y ahora que han sido liberados, Lorca los pueden nombrar “público. No pueblo”. Este público no es el mismo que entró en la sala; ha sido dramatizado, carnavalizado. Ahora ellos son la obra misma y la escena los observará. La oficialidad del teatro desaparece al mismo tiempo que el espacio cotidiano se transforma al ser tocado por el instinto carnavalesco. La obra rompe los límites oficiales, transgrede las reglas y trastoca al espectador, mutándolo en uno nuevo, quizá mejor.

El telón se levanta, la cortina azul da lugar a otro decorado del mismo color, aunque quizá no del mismo tono. 


\section{Revista Iberoamericana \\ de las Ciencias Sociales y \\ Humanísticas}

ISSN: $2395-7972$

Figura 1. Primeros niveles dramáticos de El público

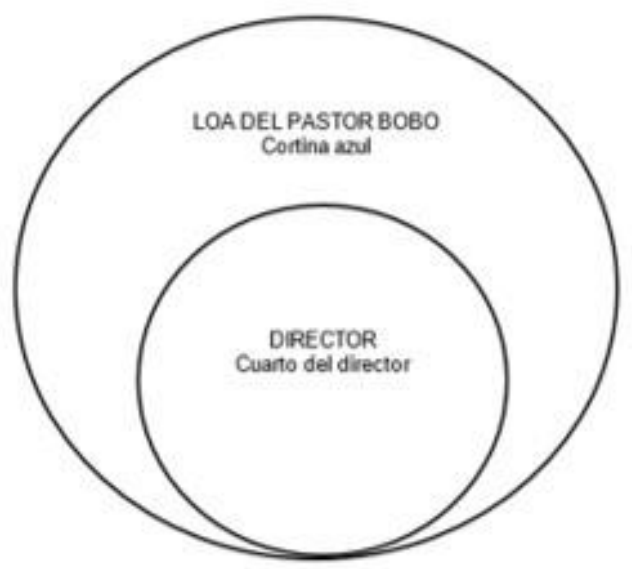

Fuente: Elaboración propia

Accedemos al drama secundario que inicia y acaba en el cuarto del director. El decorado azul, la mano y las ventanas de radiografía "sitúan la obra en una atmósfera de simbolismo surrealista" (Martínez, 1974, pp. 31-32), que, unido al juego temporal, espacial y discursivo, genera una serie de transgresiones hoy y para el espectador de la época en que se escribió el texto, quien concebía espacios más amables a su condición especular. Luis Fernández Cifuentes (1986), en relación con el público burgués de la época, dijo:

Para el espectador de la época este tipo de escenarios constituía, pues, un signo icónico de extraordinaria coherencia: era, primero, un signo familiar que se reproducía una y otra vez en casi todas las representaciones de casi todos los teatros; era, al mismo tiempo, un signo de lo familiar que remitía inmediatamente al centro de la casa y se trataba además de un signo tranquilizador: el escenario reprimía su "conciencia" de tal (su carácter de signo de algo) y ofrecía al espectador solo la imagen cabal del espacio conocido (familiar); es decir, se reducía al mínimo la diferencia entre la sala de donde venía el espectador y la que encontraba representada en el escenario, como si las puertas cerradas del salón burgués sobre el que habitualmente se levantaba el telón, simbolizaran la canonización de los horizontes morales, espirituales e intelectuales de la burguesía (p. 15).

Por surrealismo entendemos las técnicas y actitudes que facilitan la comunicación entre el mundo interior del creador y el mundo exterior, "la coexistencia de la realidad y el sueño, la intercomunicación entre las distintas esferas, el derribo de los límites tradicionales de tiempo y espacio" (Martínez N., 1974, p. 79). 


\section{Revista Iberoamericana \\ de las Ciencias Sociales y \\ Humanísticas}

ISSN: $2395-7972$

La obra, desde ese mundo surrealista, se configura en un proceso onírico. Es en la oficina del director de teatro donde se instaura el principio del segundo drama. Sueño. Recuerdo. Imaginación. Mundo interior atrapado. Ansia de liberación. Mundo inconsciente. Matrioska. Este segundo mundo dará lugar a otro, en una alusión a la verdad oculta en el fondo del ser.

Podríamos decir, dada la naturaleza onírica de todo el drama, que el conflicto íntimo y patente es un sueño dentro de otro sueño, en parte velado, que lo incluye, pero que supone un plano de referencia más profundo en la medida en que exterioriza hasta las últimas consecuencias la misma problemática: la virtualidad del amor homosexual y la posibilidad o imposibilidad de escapar a los efectos de ocultación que impone la "máscara" (Kosma, 1996, p. 78).

En el cuarto del director se establece, pues, el presente del segundo drama. El espacio se describe de un color azul al cual se le puede dar una interpretación espiritual. Una mano pintada que se puede asociar con la búsqueda de la verdad; las manos demuestran la voluntad del individuo. Las radiografías son un elemento usual en la vanguardia, así como surrealista; fotografías del interior del cuerpo, pero que aquí ocupan el sitio de las ventanas: quizá afuera se encuentre la piel de una máscara más. En ese lugar es donde se realiza el teatro al aire libre. Una oficina dentro del teatro, arte institucionalizado a partir de una cultura legalizada, es decir, aceptada, que estaría representada por este tipo de teatro para seres sin capacidad de suspiro, pues todo será predecible y entrará dentro de los patrones preestablecidos.

El acceso a un nuevo nivel es también la entrada a la perspectiva interior del personaje del Director por parte del público. Es a partir del Director que este nuevo nivel se configurará. La entrada de caballos es un recuerdo simbólico de su infancia, llave de acceso, inicio de viaje.

LOS CABALLOS. ¡Por nada! Antes te olían los pies

y nosotros teníamos tres años. Esperábamos en el retrete,

esperábamos detrás de las puertas y luego te

llenábamos la cama de lágrimas (García, 2006, p. 104).

Sumergirnos un nivel más será lo de menos; el problema quizá sea salir de él, pues ahora el aire de la caída silba al lado del Director. 


\section{Revista Iberoamericana \\ de las Ciencias Sociales y \\ Humanísticas}

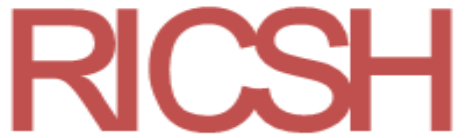

ISSN: $2395-7972$

DIRECTOR. ¡Teatro al aire libre! ¡Fuera, vamos!

¡Teatro al aire libre! ¡Fuera de aquí! (Salen [Los Caballos].

Al Criado.) Continúa. (Se sienta detrás de la mesa.)

CRIADO. Señor.

DIRECTOR. ¿Qué?

CRIADO. ¡El público!

DIRECTOR. Que pase (García, 2006, pág. 106).

La salida de Los Caballos y la entrada del Criado, una vez más, generan una repetición que contiene el ritmo y provoca un nuevo inicio. La aparición de los tres hombres da inicio al preámbulo de lo que se configurará como teatro bajo la arena. La colocación del biombo, la transformación del Director en "un muchacho vestido de raso blanco con una gran gola blanca al cuello" (García, 2006, pp. 114-115), así como la invitación que el Hombre Tres realiza a Los Caballos para que tomen asiento nos configura un nuevo escenario.

De esta manera, tenemos el primer espacio correspondiente a la convención sala y escenario y, dentro de este espacio, en la oficina del director, un nuevo espacio escénico. En este nuevo espacio el personaje se convierte en actor simbólico de su interior. En el caso concreto del Director, lo vemos aparecer como Pierrot, personaje de la comedia del arte. El desdoblamiento se da en grado inferior a la persona, máscara degradada irónicamente en personaje tipificado. En este nuevo nivel es el Hombre Uno quien funge como director del sueño interno del Director.

El texto se configura entonces como un metadrama que arropa a una metateatralidad. Desde el inicio se ven los códigos que nos refieren a una puesta en escena. El metateatro implica una puesta en escena imbricada, esto es, "una puesta en escena dentro de otra" (García, 2012, p. 232). En esta obra no aparece en su forma más pura, pues los personajes afloran como sueño o recuerdo, que no locura, del pasado del Director y lo fuerzan a representarse - pienso que es la palabra correcta - hasta que él accede. El hecho de que considere el texto un metadrama con un nivel metateatral se debe a que los personajes del primer nivel no se conciben como actores.

Desde este punto de vista nos encontramos un público desdoblado en "externo" e "interno", con lo cual el hecho especular se reafirma y se restablece su verdadera condición: la de estar asistiendo a una ficción. De tal manera que el dramaturgo juega con una ilusión a partir de la distancia representada para alcanzar su verdad. El espacio también lo encontramos 


\section{Revista Iberoamericana \\ de las Ciencias Sociales y \\ Humanísticas}

ISSN: $2395-7972$

no solo desdoblado sino fragmentándose a medida que el drama avanza. El espacio escénico se convierte en un mundo posible y real; escenario-sala, cuarto del director-escenario.

Figura 2. Espacio escénico de El público

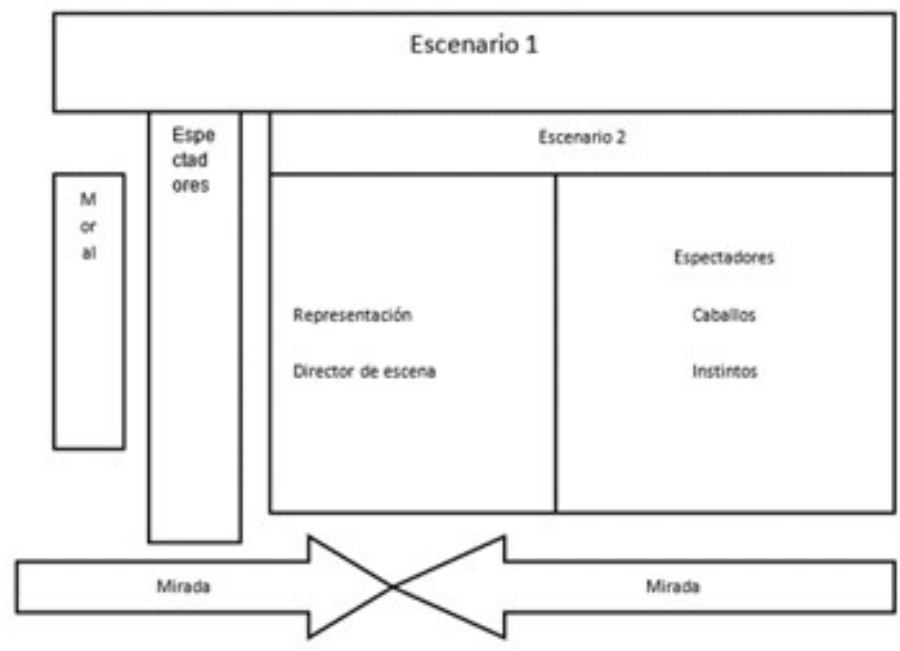

Fuente: Elaboración propia

Juego de miradas análogo al que hemos observado ya en la "Loa...": "Cortina azul. En el centro, un gran armario lleno de caretas blancas de diversas expresiones. Cada careta tiene su lucecita delante" (García, 2006, p. 99). Los cuadro segundo y tercero sostienen este juego de miradas. Pero ya en el cuadro tres la trasgresión de los niveles se comienza a percibir en un sentido claro de deformar la realidad y mezclar los planos que se han establecido. La visión del carnaval se acentúa en este momento: se deforma sistemáticamente la realidad a partir de la estética propuesta, haciendo patente, una vez más, el sentido de rebeldía social e institucional que el texto propone, en este caso, a partir de la sobreposición de niveles. El cambio social empieza por el cambio de la estética teatral: "hay que pensar en el teatro del porvenir. Todo lo que existe ahora en España está muerto" (García, 2006, p. 14). En El público, "Lorca pone en evidencia el sentido artificioso de unidad y armonía que proyecta el teatro institucionalizado" (Jerez, 2004, p. 233). La mezcla de los niveles a partir de la interiorización en el Director tiene relación con la duración del sueño y la concepción este, en un sentido donde sueño y ficción se empatan reafirmando el espacio escénico como mundo posible, sentido carnavalesco de la espacialidad. El espacio real está preñado de sueños escénicos. La figura 3 intenta explicarlo. 


\section{Revista Iberoamericana \\ de las Ciencias Sociales y \\ Humanísticas}

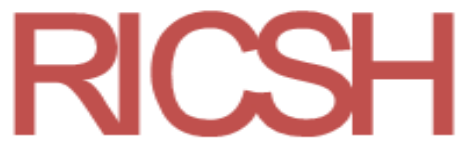

ISSN: $2395-7972$

Figura 3. Mezcla de niveles dramáticos de El público

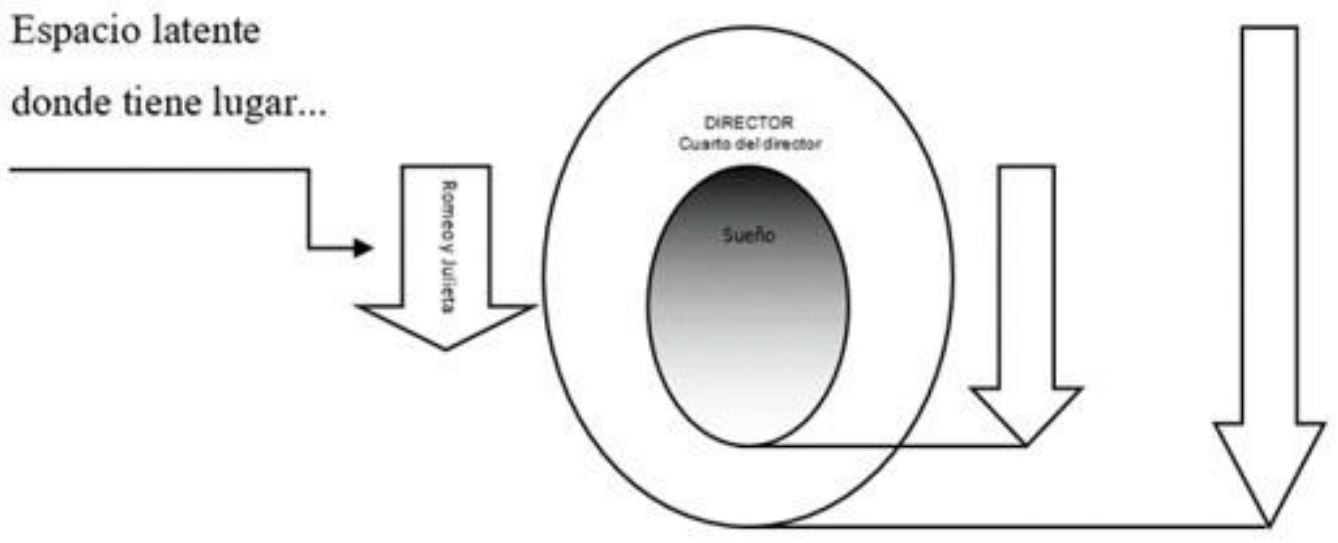

Fuente: Elaboración propia

La fragmentación de los espacios tiene relación con los niveles y las historias que se desarrollan en el drama. En el mundo interior alterno del Director de escena tenemos, por un lado, la historia del Director y, por otro, la representación de la obra Romeo y Julieta, que queda inconclusa. En el exterior sucede la rebelión contra el teatro bajo la arena. De esta manera, la superposición de los niveles dramáticos genera un rompimiento de la frontera liminar característica del teatro, lo cual acentúa el sentido carnavalesco de la obra en el cuadro cuarto de esta edición. La aparición de las damas y estudiantes en este cuadro mezcla las diferentes realidades en un juego extra e intraescénico. 


\section{Revista Iberoamericana \\ de las Ciencias Sociales y \\ Humanísticas}

ISSN: $2395-7972$

Figura 4. Superposición de niveles dramáticos de El público

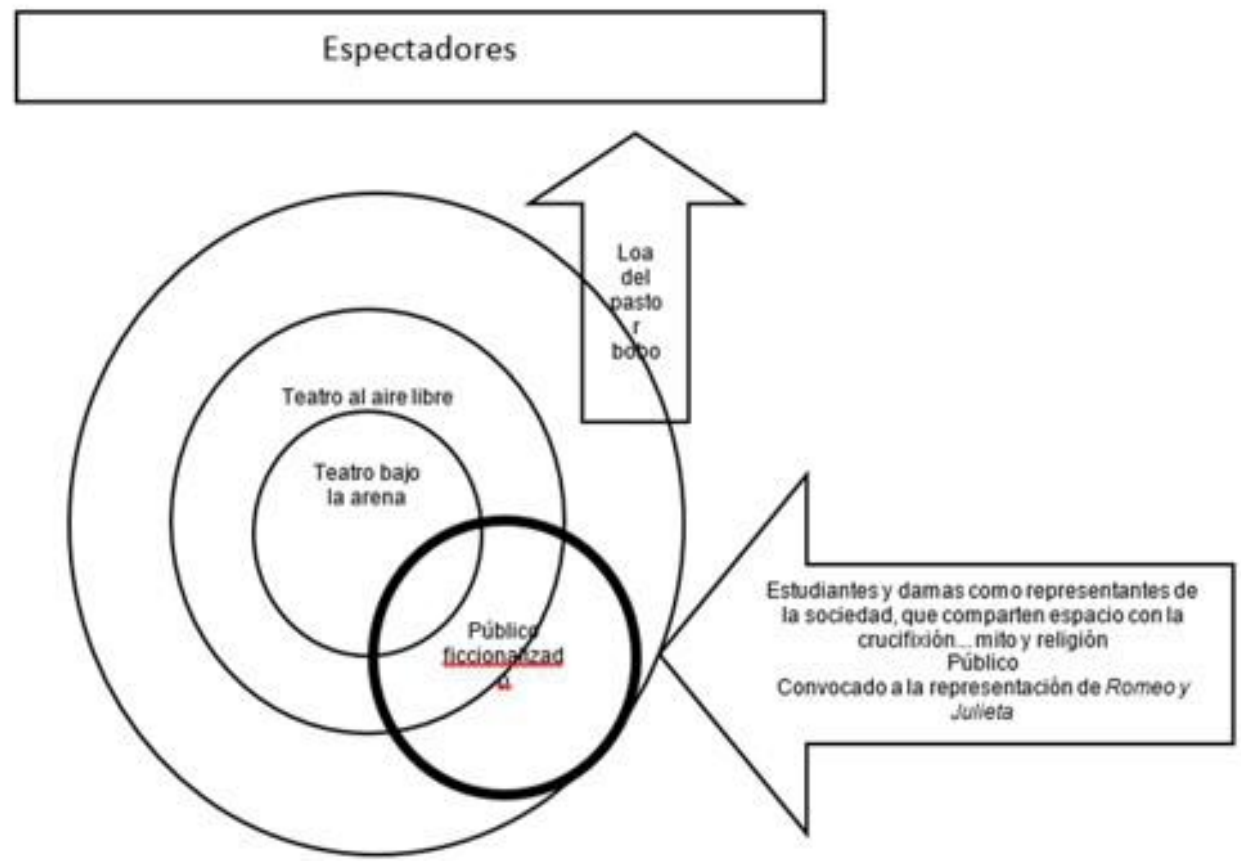

Fuente: Elaboración propia

El público, obra netamente de la vanguardia teatral, es un texto en el cual la estética y la ideología van unidas — una buena obra de teatro debe ser así-. La obra tiene un sentido de transformar el objeto del que se sirve y mediante él, a su vez, lograr la transformación del mundo al que se vincula. Estas son las dos visiones que prevalecen en la obra: por una parte, la historia de libertad que es representada por el Director y el Hombre Uno y sus diferentes mutaciones, y por otra, la que hace referencia al teatro al aire libre y el teatro bajo la arena. Pero estas dos líneas no pueden verse por separado.

En este juego de espejos, el espectador real siempre se encuentra en un teatro al aire libre. La institución está cimentada para que el escenario no sea invadido físicamente por él. En este juego de reflejos, el proceso de denegación provoca en el espectador la siguiente reflexión: "ese que está allí no soy yo como público"; la identificación no se produce. El público no pretende que el espectador lo haga, sino todo lo contrario: es en la distancia donde encontrará la verdad. Subversión, carnaval y sueños. La libertad teatral da la posibilidad poética de representar los sueños. En este juego especular el sueño es un reflejo más de un nivel de vida, una forma de relacionarse con la abstracción que acontece 


\section{Revista Iberoamericana \\ de las Ciencias Sociales y \\ Humanísticas}

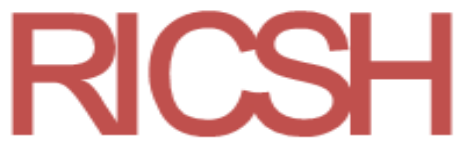

ISSN: $2395-7972$

En la mente-escena del director. Bien podría encontrar paralelo en la sustancia misma de muchos autos sacramentales y dramas alegóricos, pues, no en vano, en su forma dramática, muestran al hombre como un «campo de batalla», donde contienden personificados, en «examen de conciencia», sus fantasmas interiores, sus deseos y sus inhibiciones, cierto que matizados por un sentido teológico reservado a su propio marco cultural (Kosma, 1996, p. 258).

\section{Discusión}

Nuestro trabajo da muestra del juego de niveles que propone el autor, cada uno de ellos sirve para cubrir una parte de la diégesis ficcional planteada en el nivel inmediato anterior, el manejo espacial da muestra del sentido trasgresor propuesto por el autor, el carnaval que impregna el texto. De la mano con lo que menciona Julio Huélamo Kosma sobre el teatro bajo la arena de Lorca y que hemos citado en varios momentos, nuestro texto muestra como desde la estructura dramática el autor propone una nueva estructuración dramática que puede a su vez representar o extrapolarse a diversos niveles, generando una distancia que se aleja cada vez más a medida que avanza el texto dramático y acercándose a lo expresado por Steiner (1991):

El Surrealismo, los collages, las tácticas no figurativas con la palabra o la forma son Simplemente disfraces. Los elementos del mundo, de la existencialidad habitada, están ahí. Un «blanco sobre negro» es una instantánea de la noche; un centauro es un guion entre dos realidades manifiestas. [... ) Querámoslo o no -y esto constituye la ilimitada cárcel del lenguaje-, nuestra mirada reflexiva elabora sombras de familiaridad, de secuencia significante, a partir del verso sin sentido, de la escritura concreta y el juego aparentemente aleatorio. Alguna finalidad de realismo, de reproducción socialmente sancionada, es, hasta donde llegan la literatura y las artes plásticas, no tanto una opción libre como un hecho ineludible.

Nuestro trabajo muestra como en la obra de Lorca aquí analizada el lenguaje no alcanza para reproducir la idea y para ello es necesaria la virtualización del texto dramático en su lectura o en su representación, esto a partir del manejo espacial y de diversos niveles. El espectador observa esa "reproducción sancionada", el espectador lee esa representación. El teatro es por esencia potencia y visión, la distancia generada por el texto dramático genera una opacidad, 


\section{Revista Iberoamericana \\ de las Ciencias Sociales y \\ Humanísticas}

ISSN: $2395-7972$

esta es apoyada por los diversos niveles, el espectador se encuentra inmerso en ese mundo antes de poder entender el tema de la obra

\section{Conclusiones}

El público es una propuesta de viaje por entre las posibilidades espaciales de la escena, transitar las cavernas obscuras, los pasadizos. Invitar al público real a que se interne por los telares y las escenografías olvidadas; desvestir el teatro para que se muestre tal como es. Transformar el teatro en un escenario como reflejo de la vida. Intento perpetuo del teatro como representación de esta inasible existencia humana, conformada por códigos y reglas sobreentendidas. Lorca propone despojarse de la máscara, aquella que ensalzó Nietzsche y que el escritor granadino hermana con la falsedad y la mentira.

La transgresión propuesta por Lorca en el tema que aborda la obra se prolonga en el juego de carnavalización, el cual debe morir al finalizar la obra. Como acto de rebeldía, el carnaval no puede ser eterno, no exige continuidad, pues se institucionalizaría y su sentido desaparecería. La construcción sobre la destrucción, la muerte preñada, la renovación, no debe ni puede ser eterna; el condicionamiento tácito de la vida es su carácter efímero. Sentido carnavalesco. La muerte del Director en el cuadro quinto remite a la desaparición del carnaval. Lo que la "Loa..." había abierto al inicio de la obra caducará al final con la caída de los guantes blancos y los copos de nieve; el regreso de la oficialidad, la norma, será agradecida por los espectadores reales con sus aplausos. 
Revista Iberoamericana

de las Ciencias Sociales y

Humanísticas

ISSN: $2395-7972$

\section{Referencias}

Fernández, L. (1986). García Lorca en el teatro: la norma y la diferencia. Zaragoza, España: Prensas Universitarias de Zaragoza.

García, J. L. (2012). Cómo se comenta una obra de teatro, ensayo de método. Mexoco: Paso de gato.

García, F. (2006). El público. Madrid, España: Espasa Calpe.

Hermenegildo, A. (1999). Formas y funciones drámaticas del loco festivo: el códice de autos viejos (I). Cuadernos de Teatro Clásico, (12), 49-72.

Huerta, J. (1999). Aproximación al teatro carnavalesco. Cuadernos de Teatro Clásico, (12), $15-48$.

Jerez, C. (2004). Un Lorca desconocido: análisis de un teatro “irrepresentable”. Madrid, España: Biblioteca Nueva.

Kosma, J. H. (1996). El teatro imposible de García Lorca. Estudio sobre público. Granada, España: Servicio de Publicaciones de la Universidad de Granada.

Martínez, R. (1974). El público, amor y muerte en la obra de Federico García Lorca. Tabasco, México: Joaquín Mortiz.

Steiner, G. (1991): Presencias reales. ¿Hay algo en Lo que decimos?, Barcelona, Destino. 


\section{Juan Enrique Mendoza Zazueta}

Doctor en Filología Hispánica, por la Universidad Complutense de Madrid, es académico en la Facultad de Filosofía y Letras de la Universidad Autónoma de Sinaloa, miembro del Sistema Nacional de Investigadores (SNI), así como reconocimiento al perfil Deseable otorgado por la Secretaria de Educación Pública, además es Director de la compañía Todo Terreno Teatro. Ha realizado los proyectos representación dramática guía, corpus y metodología para alumnos de media superior. Espacio y desarraigo (2014-2015), Creación del departamento de documentación e investigación teatral en Sinaloa (2015-2016) y ha sido colaborador en diversos proyectos como Vulnerabilidad de víctimas y pérdida de identidad por desplazamiento forzado ante la violencia criminal en Sinaloa, (2017-2018). Ha publicado en revistas nacionales e internacionales y es autor del libro Indagaciones Teatrales (Colección Palabras del Humaya, IMC, 2015), así como coordinador del libro Ética, salud y comunidad: los desafíos de las artes escénicas en el siglo XXI, (CITRU-UAS, 2017). 